Materiais Lignocelulósicos: Caracterização e Produção de Briquetes

\author{
Nakashima, G. T.; Adhmann, I. C. S.; Hansted, A. L. S.; Belini, G. B.; \\ Waldman, W. R.; Yamaji, F. M.*
}

Rev. Virtual Quim., 2017, 9 (1), 150-162. Data de publicação na Web: 21 de novembro de 2016

http://rvq.sbq.org.br

\title{
Lignocellulosic Materials: Characterization and Production of Briquettes
}

Abstract: According to the environmental and energy global scenario, biomass emerges as a promising source of energy for its availability, low emissions of greenhouse gases and it is a renewable source. However, the disadvantages in the use of biomass as problems with transportation, handling, storage and low calorific values impair its use for energy purposes. Therefore, to improve its use, compression biomass becomes an efficient alternative. Briquetting is a process that changes the biomass to a material having a regular shape, increase the density with a higher calorific value per volume. However, biomass is a heterogeneous material, and its characterization is needed to better understand their properties. The most commonly used tests are: moisture content, density, particle size, proximate analysis, calorific value, extractives content and lignin content. To produce a fuel with greater efficiency and higher value added, it is necessary that the briquette present a high calorific value, high density, low ash content, has good mechanical strength and dimensional stability.

Keywords: Biomass; Bioenergy; Procedure; Renewable energy.

\section{Resumo}

Diante do cenário ambiental e energético mundial, a biomassa surge como uma fonte de energia promissora pela sua disponibilidade, baixas emissões de gases do efeito estufa e por ser uma fonte renovável. Porém, as desvantagens no uso da biomassa como problemas com transporte, manuseio, armazenamento e baixo poder calorífico prejudicam seu uso para a fins energéticos. Logo, para melhorar seu uso, a compactação da biomassa se torna uma eficiente alternativa. A briquetagem é um processo que muda a biomassa para um material com um formato regular, maior densidade e com maior poder calorífico por volume. No entanto, sendo a biomassa um material heterogêneo, é necessário a sua caracterização para melhor entender suas propriedades. As análises mais utilizadas são: o teor de umidade, a densidade, a granulometria, a análise imediata, o poder calorífico, o teor de extrativos e o teor de lignina. Para produzir um combustível com maior eficiência e maior valor agregado, é preciso que o briquete apresente um alto poder calorífico, densidade elevada, baixo teor de cinzas, tenha uma boa resistência mecânica e estabilidade dimensional.

Palavras-chave: Biomassa; Bioenergia; Procedimentos; Energia renovável.

* Universidade Federal de São Carlos, Centro de Ciências e Tecnologias para Sustentabilidade, Departamento de Ciências Ambientais, Campus Sorocaba, CEP 18052-780, Sorocaba-SP, Brasil.

Mfmyamaji@ufscar.br

DOI: 10.21577/1984-6835.20170012 


\section{Materiais Lignocelulósicos: Caracterização e Produção de Briquetes}

\section{Gabriela T. Nakashima, Isis C. S. Adhman, Ana L. S. Hansted, Gabriela B. Belini, Walter R. Waldman, Fabio M. Yamaji*}

Universidade Federal de São Carlos, Centro de Ciências e Tecnologias para Sustentabilidade, Departamento de Ciências Ambientais, Campus Sorocaba, CEP 18052-780, Sorocaba-SP, Brasil.

* fmyamaji@ufscar.br

Recebido em 18 de novembro de 2016. Aceito para publicação em 20 de novembro de 2016

\section{Introdução}

\section{Matérias-primas para briquetagem}

\section{Caracterização da biomassa e procedimentos}

3.1. Teor de umidade

3.2. Densidade a granel

3.3. Classificação granulométrica

3.4. Análise imediata

3.5. Poder calorífico superior

3.6. Análise química

\section{Briquetes}

4.1. Análise química

4.2. Análise de briquetes

\section{Introdução}

É esperado um aumento no consumo de energia mundial para as próximas décadas. ${ }^{1,2}$ Para suprir a necessidade energética será preciso o desenvolvimento e implantação de novas tecnologias com baixas emissões de carbono, ${ }^{2}$ destacando o uso da energias renováveis que tem uma estimativa de crescimento médio de $2,9 \%$ ao ano com projeção até $2040 .{ }^{1}$

Atualmente, o Brasil conta com 41,2 \% da oferta interna de energia provindo de fontes energéticas renováveis. ${ }^{3}$ No entanto, baseando-se no cenário 2DS, onde estudos apontam a limitação do aumento da temperatura global em $2{ }^{\circ} \mathrm{C}$, o Brasil necessita que aproximadamente $70 \%$ de sua matriz seja de fontes renováveis em 2050. ${ }^{1}$

O maior representante das renováveis na matriz energética brasileira, é a biomassa com $16,9 \%$ da oferta interna de energia. ${ }^{3} \mathrm{~A}$ energia de biomassa é uma fonte bastante promissora no Brasil, que possui 517 termelétricas abastecidas a biomassa, com potência instalada de aproximadamente de Rev. Virtual Quim. |Vol 9| |No. 1| |150-162| 
$14 \mathrm{GW} .^{4}$

A biomassa é definida como "um material orgânico não fóssil de origem biológica". ${ }^{5} \mathrm{O}$ Brasil possui como vantagens no uso deste tipo de energia: as condições edafoclimáticas propícias, ${ }^{4}$ resíduos provenientes de culturas florestais, agrícolas, sólidos urbanos e de atividades pecuaristas disponíveis durante o ano todo, ${ }^{6}$ baixa emissões de gases $\mathrm{NO}_{\mathrm{x}} \mathrm{e}$ $\mathrm{SO}_{2}{ }^{7}$ Porém, a biomassa apresenta alguns inconvenientes como $\mathrm{O}$ alto teor de umidade $^{8-9} \quad$ o transporte $^{6,10,11} \quad 0$ manuseio $^{6,10,11}$ e o armazenamento, ${ }^{6,8,10,11}$ além de ser um material heterogêneo, ${ }^{12} \mathrm{e}$ com baixo poder calorífico quando comparado aos combustíveis fósseis. ${ }^{6,9,12}$

Para diminuir os problemas do uso e melhorar a eficiência de energia de biomassa, a densificação é um meio de aperfeiçoar a biomassa para gerar um produto final com maior valor agregado, na forma de pellets e briquetes (Figura 1). A briquetagem é definida como "um processo de densificação que melhora as suas características de manuseio, aumenta o seu poder calorífico por volume, reduz o custo de transporte e produz um combustível uniforme, limpo, e estável". ${ }^{13}$

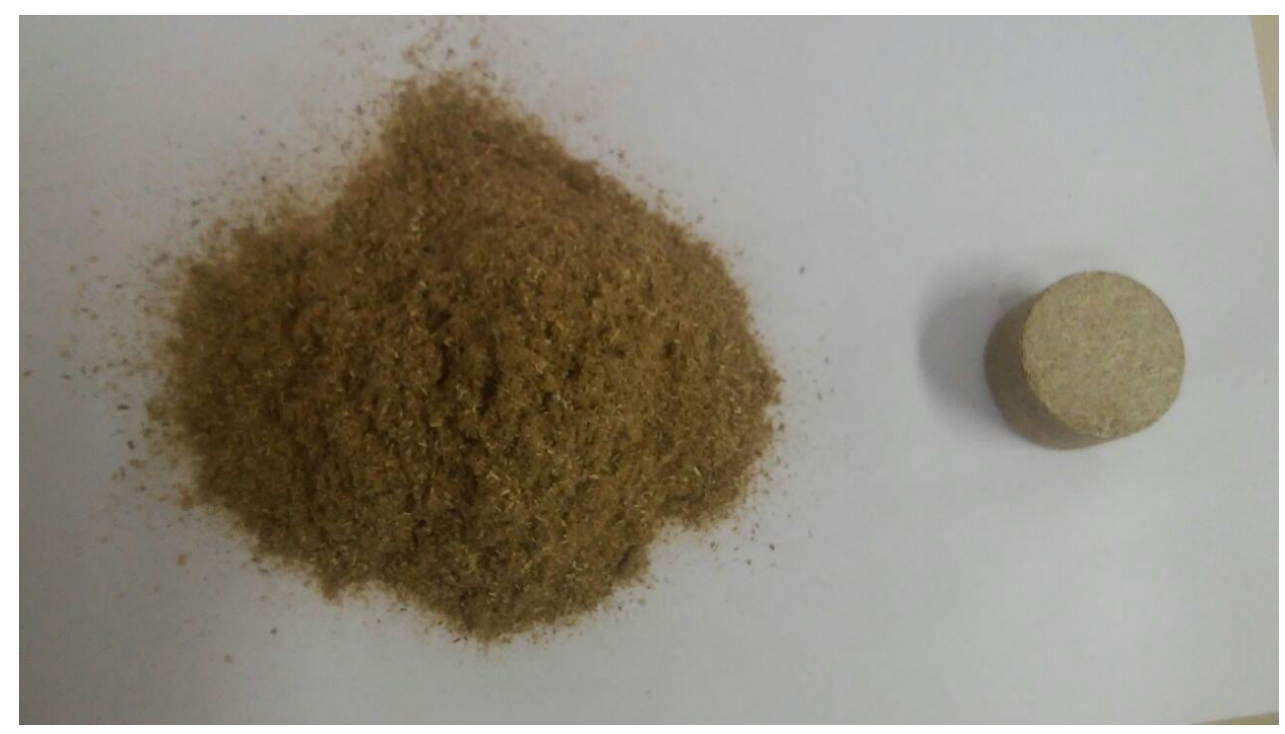

Figura 1. A mesma quantidade de biomassa em formato a granel e na sua forma compactada

\section{Matérias-primas para briquetagem}

Podem ser utilizadas diversas biomassas com a finalidade de produção de briquetes. Os resíduos lignocelulósicos, em geral são opções para obtenção de biocombustíveis sólidos com alta qualidade. Entre as opções disponíveis, merecem destaque os resíduos florestais, madeireiros, agrícolas, cavaco, bambu, carvão, entre outros. ${ }^{14}$

A disponibilidade destes recursos naturais no Brasil favorece a utilização da biomassa vegetal para a geração de energia. ${ }^{10}$ Quanto ao setor florestal, atualmente existem 7,2 milhões de hectares de florestas plantadas, e este setor gera grande quantidade de resíduos. Em 2015, o país produziu cerca de 47 milhões de toneladas de resíduos florestais. ${ }^{15}$ No setor agrícola, a cana-deaçúcar, apresenta um plantio de aproximadamente 9 milhões de hectares, com geração de resíduo que supera os 184 milhões de toneladas por ano. ${ }^{16}$ Atualmente, no país os materiais mais utilizados para a produção de energia são o bagaço de canade-açúcar, cavacos, a lenha e o carvão vegetal. ${ }^{15}$

Com menor expressividade, porém com potencial energético significativo, estão os 
materiais produzidos em baixa quantidade, 0 que dificulta a utilização em escala comercial. Neste âmbito podem ser citadas algumas gramíneas como o capim elefante, poda de jardim, poda urbana, sementes oleaginosas. ${ }^{17-18}$

\section{Caracterização da biomassa e procedimentos}

Para que sejam produzidos briquetes de boa qualidade, é imprescindível a realização da caracterização do material a ser utilizado, para verificar se a biomassa apresenta características térmicas desejáveis como um combustível. ${ }^{19}$

$$
T U=\frac{\text { PUi-PUf }}{\text { PUf }} \times 100
$$

Onde:

TU: Teor de umidade (\%);

PUi: Massa da biomassa inicial (úmida) (g);

PUf: Massa da biomassa final (seca) (g).

$\mathrm{O}$ alto teor de umidade prejudica o comportamento combustível do material, fazendo com que haja perda energia para que a biomassa úmida reduza seu teor de umidade e comece a produzir calor. Resultando em um combustível de baixo poder. ${ }^{9,11,21}$ É aconselhável que o teor de umidade esteja entre 10 e $15 \% .{ }^{11}$

Um trabalho realizado com a biomassa de leucena (Leucaena leucocephala), uma espécie invasora no Brasil, usa o briquete como alternativa para explorar este
As análises primordiais para a caracterização da biomassa são: teor de umidade, ${ }^{8,20-22}$ densidade ${ }^{21}$ granulometria, ${ }^{23-}$ ${ }^{27}$ análise imediata, ${ }^{8,9,20,21}$ poder calorífico, ${ }^{9,20-}$ ${ }^{21}$ teor de extrativos, ${ }^{27-28}$ teor de lignina. ${ }^{21,28,29}$

\subsection{Teor de Umidade}

A determinação do teor de umidade é realizado com base na norma ASTM E871$2013 .^{30}$ Após a coleta da biomassa, são separadas amostras aleatoriamente. As amostras são pesadas e levadas à estufa com uma temperatura de 102 ㅇ. O O material é mantido na estufa até atingir massa constante. O cálculo do teor de umidade (base seca) é dado pela Equação 1.

Eq. 1

indivíduo, pois trata-se de uma espécie de rápido crescimento. A pesquisa desenvolvida utilizou três tipos de umidade para biomassa e concluiu que o teor de umidade de $12 \%$ é mais indicado para a produção de briquetes de leucena. ${ }^{31}$

\subsection{Densidade a granel (massa seca)}

A determinação da densidade da biomassa é baseada na norma ABNT NBR $6922 / 81,{ }^{32}$ sendo realizada em um recipiente de volume e formato conhecidos. As amostras da biomassa seca são inseridas num recipiente até completar o volume desejado, depois é anotada a massa da amostra. A densidade a granel é dada pela equação (Equação 2).

$$
\begin{array}{ll}
\mathrm{Dg}=\frac{\mathrm{Ms}}{\mathrm{Vr}} & \text { Eq. } 2
\end{array}
$$


Onde:

Dg: Densidade a granel (g.cm $\left.{ }^{-3}\right)$;

Ms: Massa seca da amostra (g);

Vr: volume do recipiente utilizado $\left(\mathrm{cm}^{3}\right)$.

\subsection{Classificação granulométrica}

A classificação granulométrica é baseada na norma ASTM D293-96, ${ }^{33}$ e pode ser realizada com a biomassa in natura e/ou após trituração (ou moagem). Desta forma, as peneiras são selecionadas de acordo com os tamanhos de partículas da biomassa. As peneiras selecionadas juntamente com a tampa e o fundo são colocados no agitador mecânico de partículas, com abertura das malhas em ordem crescente da base para o topo. Para uma classificação completa da granulometria é preciso que não mais que 25 $\%$ da biomassa fique retido em uma única peneira.

De acordo com Silva e colaboradores ${ }^{24}$ e Gonçalves e colaboradores ${ }^{26}$, a granulometria é um fator que pode interferir no processo de briquetagem. Em geral, as partículas menores tem maior afinidade com a água e criam mecanismos de adesão entre elas, resultando em um produto de maior durabilidade. ${ }^{25}$

Um estudo utilizou a granulometria para melhorar as características de briquetes a partir de resíduos com dificuldade de formação que foram: a palha de milho, o bagaço de cana-de-açúcar, a poda de jardim

$$
T C=\frac{P f-P c}{m i} \times 100
$$

Onde:

$\mathrm{TC}=$ Teor de Cinzas (\%);

$\mathrm{Pf}=$ Peso do cadinho + amostra final (g);

$\mathrm{Pc}=$ Peso do cadinho $(\mathrm{g})$;

$\mathrm{Mi}=$ massa da amostra inicial (g). e o capim-elefante. O uso de partículas mais finas ajudou na compactação, resultando em briquetes com maior resistência mecânica e densidade. ${ }^{17}$

\subsection{Análise imediata}

A análise imediata é composta pelos testes de teor de cinzas, teor de voláteis e teor de carbono fixo. Para as análises de teor de cinzas e teor de voláteis é necessário que as amostras estejam secas (0 \%) e é recomendado utilizar a granulometria que passa pela peneira de 40 mesh e fica retida na peneira de 60 mesh. É importante que o ensaio seja feito pelo menos em duplicata e que, previamente, seja realizada uma calcinação dos cadinhos de porcelana.

\subsubsection{Teor de Cinzas}

O teor de cinzas foi baseado na norma ASTM D1102-84. ${ }^{34}$ O cadinho de porcelana (previamente calcinado) é pesado e é utilizado aproximadamente $1,0 \mathrm{~g}$ de biomassa por cadinho. O cadinho com a biomassa é levado para capela para uma préqueima em bico de Bünsen até levantar chama e, logo após, é colocado na mufla em $600{ }^{\circ} \mathrm{C}$ por seis horas. $\mathrm{O}$ cadinho é resfriado em dessecador e pesado em temperatura ambiente. $\mathrm{O}$ cálculo do teor de cinzas é dado pela Equação 3.

\section{Eq. 3}

A biomassa é um material muito heterogêneo podendo ser composta por materiais orgânicos e inorgânicos, em diferentes quantidades. ${ }^{35}$ Algumas biomassas podem conter maior quantidade de materiais inorgânicos presentes na sua composição ou estarem presentes na forma de contaminantes. Estas substâncias inorgânicas 
que são residuais na carbonização da biomassa, são chamadas de cinzas.

$O$ alto teor de cinzas além de reduzir o poder calorífico, ${ }^{9}$ pode também gerar maior custo com o manuseio já que é necessário a retirada deste resíduo dos fornos e/ou caldeiras. ${ }^{21}$ Ainda, as cinzas apresentam um alto nível de minerais alcalinos que juntamente com a sílica, podem se fundir e/ou depositar nas paredes diminuindo a eficiência das caldeiras ou causar maior desgaste nos equipamentos. ${ }^{10,21}$

$$
T V=\frac{P i-P f}{m i} \times 100
$$

Onde:

$\mathrm{TC}=$ Teor de Voláteis (\%);

$\mathrm{Pi}=$ Peso do cadinho + amostra inicial (g);

$\mathrm{Pf}=$ Peso do cadinho + amostra final (g);

$\mathrm{mi}=$ massa da amostra inicial (g).

\subsubsection{Teor de Voláteis}

O teor de voláteis é baseado na norma ASTM E872-82. ${ }^{36}$ Em um cadinho de porcelana com tampa de massa conhecida é colocado aproximadamente $1,0 \mathrm{~g}$ de material. O cadinho com amostra e tampa é levado para a mufla a $900^{\circ} \mathrm{C}$, durante três minutos com a porta da mufla aberta e nos próximos sete minutos com a porta fechada. O cadinho é resfriado em dessecador e pesado em temperatura ambiente. $O$ cálculo do teor de voláteis é dado pela Equação 4.

Eq. 4

\subsubsection{Carbono Fixo}

O carbono fixo é resultado da Equação 5.

$$
C F=100-(T C+T V) \quad \text { Eq. } 5
$$

Onde:

$\mathrm{CF}=$ Carbono fixo (\%);

$\mathrm{TC}=$ Teor de cinzas (\%);

TV= Teor de voláteis (\%).

\subsection{Poder Calorífico Superior}

A análise de poder calorífico superior (PCS) é adaptada da norma ASTM D586513. ${ }^{37}$ São utilizadas pelos menos duas amostras da biomassa seca com granulometria entre 40 e 60 mesh. As amostras são analisadas pela bomba calorimétrica.

A tabela 1 apresenta os resultados obtidos para a análise imediata e o poder calorífico de diversos tipos de biomassa, realizados pelo do grupo de pesquisa Biomassa e Bioenergia da Universidade Federal de São Carlos. 
Tabela 1. Valores de análise imediata e poder calorífico superior encontrados para diferentes tipos de biomassas.

\begin{tabular}{|c|c|c|c|c|}
\hline Biomassa & $\begin{array}{c}\text { Teor de cinzas } \\
\text { (\%) }\end{array}$ & $\begin{array}{c}\text { Teor de } \\
\text { Voláteis (\%) }\end{array}$ & $\begin{array}{l}\text { Carbono } \\
\text { fixo (\%) }\end{array}$ & $\begin{array}{c}\text { Poder } \\
\text { Calorífico } \\
\text { Superior } \\
\left(\mathrm{MJ.kg}^{-1}\right)\end{array}$ \\
\hline Finos de carvão vegetal+10\%amido ${ }^{38}$ & 18,33 & 27,50 & 54,17 & 18,29 \\
\hline Carvão Vegetal+2,5\%amido ${ }^{39}$ & 2,37 & 33,19 & 64,44 & 30,79 \\
\hline Carvão Mineral+2,5\%amido ${ }^{39}$ & 42,35 & 16,39 & 41,25 & 15,90 \\
\hline Eucalipto $^{26}$ & 0,44 & 88,65 & 10,80 & 17,69 \\
\hline Eucalipto $^{40}$ & 0,30 & 82,20 & 17,50 & 19,49 \\
\hline Eucalipto $^{41}$ & 1,35 & 79,35 & 19,30 & 18,13 \\
\hline Serragem de Eucalipto ${ }^{24}$ & 1,57 & 80,54 & 17,90 & 19,18 \\
\hline Serragem de Eucalipto ${ }^{42}$ & 1,60 & 82,56 & 15,83 & 19,68 \\
\hline Serragem de Eucalipto ${ }^{43}$ & 1,32 & 83,48 & 15,20 & 18,56 \\
\hline Pinus $^{44}$ & 0,14 & 77,78 & 22,07 & - \\
\hline Serragem de Pinus ${ }^{24}$ & 0,23 & 81,16 & 18,61 & 20,32 \\
\hline Serragem de Pinus ${ }^{42}$ & 0,76 & 83,61 & 15,62 & 20,09 \\
\hline Serragem de Pinus ${ }^{43}$ & 0,45 & 82,76 & 16,79 & 19,56 \\
\hline Serragem de Candeia ${ }^{45}$ & 1,48 & 76,02 & 22,50 & 19,54 \\
\hline Guapuruvu $^{46}$ & 2,92 & 76,25 & 20,83 & 18,89 \\
\hline Leucena $^{47}$ & 4,98 & 75,33 & 20,68 & 18,60 \\
\hline Pau-jacaré ${ }^{47}$ & 1,83 & 77,27 & 20,29 & 18,96 \\
\hline Serragem de Seringueira ${ }^{42}$ & 1,51 & 78,44 & 20,03 & 19,56 \\
\hline Serragem de Laranjeira ${ }^{42}$ & 1,21 & 82,78 & 16,00 & 18,92 \\
\hline Bambusa vulgaris ${ }^{48}$ & 7,19 & 75,54 & 17,27 & - \\
\hline Bambusa tuldoides ${ }^{40}$ & 3,00 & 75,20 & 21,80 & 18,89 \\
\hline Bambusa vulgaris ${ }^{40}$ & 2,50 & 74,70 & 22,80 & 19,51 \\
\hline Dendrocalamus asper ${ }^{40}$ & 2,10 & 75,00 & 23,00 & 18,94 \\
\hline Poda de Jardim ${ }^{17}$ & 4,58 & 82,01 & 13,41 & 16,65 \\
\hline Capim elefante $\mathrm{e}^{17}$ & 3,80 & 78,98 & 17,22 & 17,20 \\
\hline Bagaço de cana-de-açúcar ${ }^{43}$ & 8,62 & 75,86 & 15,52 & 17,31 \\
\hline Bagaço de cana-de-açúcar ${ }^{17}$ & 1,58 & 84,03 & 14,39 & 17,56 \\
\hline Bagaço de cana-de-açúcar ${ }^{45}$ & 2,43 & 84,70 & 12,87 & 17,57 \\
\hline Bagaço de cana-de-açúcar²4 & 1,42 & 80,69 & 17,89 & 18,54 \\
\hline Palha de cana-de-açúcar ${ }^{24}$ & 12,19 & 70,59 & 17,22 & 15,63 \\
\hline Palha de cana-de-açúcar ${ }^{49}$ & 5,68 & 77,50 & 16,81 & 17,49 \\
\hline Palha de milho ${ }^{17}$ & 1,92 & 80,73 & 17,35 & 16,80 \\
\hline Fibra de $\operatorname{coco}^{49}$ & 3,71 & 74,01 & 22,28 & 18,24 \\
\hline Casca de Licuri ${ }^{50}$ & 7,38 & 75,73 & 16,89 & 19,46 \\
\hline Epicarpo residual do Pinhão Manso ${ }^{44}$ & 7,71 & 65,56 & 26,72 & 17,07 \\
\hline
\end{tabular}




\subsection{Análise química}

O teor de extrativos e o teor de lignina além de ajudar no poder calorífico da biomassa, ${ }^{28,51}$ são componentes que ajudam na adesão de partículas, quando em temperaturas elevadas. ${ }^{25}$

\subsubsection{Teor de Extrativos}

A biomassa seca com granulometria entre 40 e 60 mesh é dividida em amostras de aproximadamente $1,0 \mathrm{~g}$ e são colocadas cada uma em papel filtro de massa conhecida. É aconselhável que seja feito pelo menos três repetições.

\subsubsection{Extrativos em solvente orgânico}

Com base na norma Tappi T204 cm-97,, os papeis com as amostras são colocadas no sistema Soxhlet, preenchendo os frascos com aproximadamente $200,0 \mathrm{~mL}$ de ciclo-hexano 1:1 etanol. As repetições devem permanecer no extrator no mínimo durante 24 ciclos. Depois da extração, o material deve ser seco em estufa até peso constante e pesado.

As mesmas amostras passadas pelo ciclohexano 1:1 etanol, devem passar pelo mesmo procedimento em etanol puro por mais 24 ciclos, deve ser seco em estufa e pesado.

\subsubsection{Extrativos em água quente}

Baseado na norma Tappi T207 cm-99, ${ }^{53}$ as amostras já extraídas por solvente devem passar por extração em água quente para a remoção de componentes inorgânicos, açúcares e amidos. Aproximadamente 10,0 g de amostra são colocadas em um Erlenmeyer de $250,0 \mathrm{~mL}$ com 100,0 mL de água destilada quente. Durante três horas, o Erlenmeyer deve ficar em banho-maria com nível de água fervente constante. Após a extração, o material deve ser filtrado em um papel filtro (de massa conhecida) com o auxílio de uma bomba a vácuo. O papel filtro com a amostra deve ser seco em estufa e pesado quando o peso de sua massa estiver constante.

\subsubsection{Teor de Lignina}

A determinação de lignina insolúvel é baseada na norma Tappi T222 om- $98,{ }^{54}$ realizada em triplicata. A amostra de $1,0 \mathrm{~g}$ seco e sem extrativos é submetida a hidrólise com $15,0 \mathrm{~mL}$ de $\mathrm{H}_{2} \mathrm{SO}_{4} 72 \%$ em um Erlenmeyer de $250,0 \mathrm{~mL}$, durante 2 horas com agitação constante. A solução é transferida para um Erlemenmeyer de 1,0 L com $300,0 \mathrm{~mL}$ de água destilada. A solução deve ser completada água destilada para que alcance uma concentração de $3 \%$ de $\mathrm{H}_{2} \mathrm{SO}_{4}$. $\mathrm{A}$ solução é fervida durante quatro horas, mantendo o volume constante. Após as quatro horas, é preciso esperar o material assentar para filtrar a lignina. Depois da filtragem, pode-se lavar a lignina livre de ácido com água quente. A lignina deve secar em estufa até massa constante e deve ser pesada.

A tabela 2 apresenta alguns resultados obtidos para o teor de lignina insolúvel e o teor de extrativos de diversas biomassas, realizados pelo grupo de pesquisa Biomassa e Bioenergia da Universidade Federal de São Carlos. 
Tabela 2. Valores de Teor de lignina insolúvel e teor de extrativos de diferentes tipos de biomassa

\begin{tabular}{lcc}
\hline \multicolumn{1}{c}{ Biomassa } & Lignina insolúvel (\%) & Teor de Extrativos (\%) \\
\hline Eucalipto $^{41}$ & 17,12 & 15,88 \\
Serragem de Eucalipto $^{42}$ & 26,52 & 8,00 \\
Serragem de Eucalipto $^{43}$ & 25,44 & 5,86 \\
Serragem de Pinus $^{42}$ & 24,64 & 19,15 \\
Serragem de Pinus $^{43}$ & 27,65 & 6,47 \\
Leucena $^{47}$ & 22,61 & 16,37 \\
Pau-jacaré $^{47}$ & 27,88 & 16,00 \\
Serragem de Seringueira $^{42}$ & 20,49 & 9,87 \\
Serragem de Laranjeira $^{42}$ & 39,24 & 21,76 \\
Bagaço de cana-de-açúcar $^{43}$ & 19,11 & 11,82 \\
Casca de Licuri $^{50}$ & 36,86 & 46,75 \\
\hline
\end{tabular}

\section{Briquetes}

\subsection{Produção de briquetes}

São utilizados $20,0 \mathrm{~g}$ de biomassa para a produção de briquetes. A biomassa é colocada no molde cilíndrico com diâmetro interno de $35,0 \mathrm{~mm}$ e $16,0 \mathrm{~cm}$ de altura e com a ajuda de uma prensa hidráulica, a biomassa é densificada a uma pressão de 1247,25 kgf. $\mathrm{cm}^{-2}$ durante 30 segundos, sem uso de aquecimento e sem aglutinantes.

\subsection{Análise dos briquetes}

A caracterização da biomassa anteriormente descrita, além de variáveis relacionadas aos equipamentos utilizados para a densificação são fatores que podem afetar a resistência e a durabilidade dos briquetes. ${ }^{25}$ A resistência e a durabilidade dos briquetes são importantes parâmetros para facilitar o transporte, o manuseio e o armazenamento.

\subsubsection{Estabilidade dimensional}

Após a briquetagem, é preciso medir a estabilidade das dimensões do briquetes formado, através do paquímetro digital, o período em que as medições devem ocorrer, pode variar, e serão interrompidos quando os briquetes já não apresentarem alterações, ou seja, estejam estabilizados.

Com os valores obtidos também é possível calcular a densidade aparente dos briquetes.

\subsubsection{Resistência mecânica}

A resistência mecânica deve ser determinada por meio do ensaio mecânico de tração por compressão diametral, através da máquina universal EMIC com célula de carga de $500 \mathrm{~N}$ a uma velocidade de $3 \mathrm{~mm} / \mathrm{min}$, adaptado da norma ABNT NBR $7222 / 11 .^{55}$ 
O teste de friabilidade é realizado com o auxílio do equipamento friabilômetro, com dimensões internas de $30 \times 30 \times 10 \mathrm{~cm}$. De 3 a 5 briquetes são colocados no friabilômetro a 35 rotações por minuto, durante um período de 15 minutos, adaptado da norma ABNT NBR $8740 / 85 .{ }^{58}$ Posteriormente é feita a pesagem do material que se desprendeu do briquete, através da diferença do material retido na peneira de 5 mesh.

A tabela 3 apresenta os resultados obtidos para a tensão máxima, friabilidade e densidade aparente de briquetes (diversos materiais), realizados pelo do grupo de pesquisa Biomassa e Bioenergia da Universidade Federal de São Carlos.

Tabela 3. Valores obtidos para tensão máxima, friabilidade e densidade aparente dos briquetes a partir de diversas matérias-primas

\begin{tabular}{|c|c|c|c|}
\hline Briquetes & $\begin{array}{l}\text { Tensão Máxima } \\
\text { (MPa) }\end{array}$ & Friabilidade (\%) & $\begin{array}{c}\text { Densidade } \\
\text { aparente } \\
\left(\mathrm{kg} \cdot \mathrm{m}^{-3}\right)\end{array}$ \\
\hline $\begin{array}{lcc}\text { Finos } & \text { de } & \text { carvão } \\
\text { vegetal+10\%amido }^{38} & \end{array}$ & - & - & 1117,00 \\
\hline Carvão Vegetal+2,5\%amido ${ }^{39}$ & 0,08 & 56,27 & 918,60 \\
\hline Carvão Mineral+2,5\%amido ${ }^{39}$ & 0,26 & 38,60 & 1526,60 \\
\hline Eucalipto $^{26}$ & 0,50 & 8,29 & 1007,45 \\
\hline Eucalipto $^{40}$ & - & 4,00 & 1360,00 \\
\hline Serragem de Eucalipto ${ }^{24}$ & 1,22 & pouco friável & 920,00 \\
\hline Serragem de Eucalipto ${ }^{43}$ & 1,01 & - & 871,84 \\
\hline Pinus $^{44}$ & 0,48 & - & - \\
\hline Serragem de Pinus ${ }^{24}$ & 0,70 & frabilidade média & 1000,00 \\
\hline Serragem de Pinus ${ }^{43}$ & 0,45 & - & 852,54 \\
\hline Serragem de Candeia ${ }^{45}$ & 1,00 & - & - \\
\hline Guapuruvu $^{46}$ & 0,25 & frabilidade média & 813,00 \\
\hline Leucena $^{47}$ & 0,41 & 4,07 (muito pouco) & - \\
\hline Pau-jacaré ${ }^{47}$ & 0,53 & 5,17 (muito pouco) & - \\
\hline Bambusa tuldoides $^{40}$ & - & 9,00 & 1150,00 \\
\hline Bambusa vulgaris ${ }^{40}$ & - & 2,00 & 1380,00 \\
\hline Dendrocalamus asper ${ }^{40}$ & - & 7,00 & 1360,00 \\
\hline Poda de Jardim ${ }^{17}$ & 0,79 & - & 1066,60 \\
\hline Capim elefante $\mathrm{e}^{17}$ & 0,53 & - & 956,90 \\
\hline Bagaço de cana-de-açúcar ${ }^{43}$ & 0,61 & - & 840,47 \\
\hline Bagaço de cana-de-açúcar ${ }^{17}$ & - & - & 949,50 \\
\hline Bagaço de cana-de-açúcar ${ }^{45}$ & 0,26 & - & - \\
\hline Bagaço de cana-de-açúcar ${ }^{24}$ & 0,27 & muito friável & 880,00 \\
\hline Palha de cana-de-açúcar ${ }^{24}$ & 0,98 & pouco friável & 1110,00 \\
\hline Palha de cana-de-açúcar ${ }^{49}$ & 0,24 & 59,4 (muito) & - \\
\hline Palha de milho ${ }^{17}$ & 0,12 & - & 934,30 \\
\hline Fibra de $\operatorname{coco}^{49}$ & 0,37 & 6,62 (muito pouco) & - \\
\hline
\end{tabular}


Para produzir um combustível sólido com maior eficiência e maior valor agregado, é preciso que o briquete apresente um alto poder calorífico, densidade elevada, baixo teor de cinzas, tenha uma boa resistência mecânica e estabilidade dimensional.

\section{Agradecimentos}

Os autores agradecem as agências CAPES, pelas bolsas concedidas e CNPQ, pelo auxílio.

\section{Referências Bibliográficas}

${ }^{1}$ EIA - U.S. Energy Information Administration. Annual energy outlook 2016 with projections to 2040, 2016. [Link]

${ }^{2}$ IEA - International Energy Agency. Energy Technology Perspectives 2015, 2015. [Link]

${ }^{3}$ EPE - Empresa de Pesquisa Energética. Balanço Energético Nacional 2016, 2016. [Link]

${ }^{4}$ Tolmasquim, M. T. Energia Renovável: Hidráulica, Biomassa, Eólica, Solar, Oceânica / Mauricio Tiomno Tolmasquim (coord.). - EPE: Rio de Janeiro, 2016. [Link]

${ }^{5}$ NREL, 2014 Renewable Energy Data Book, 2015. [Link]

${ }^{6}$ Felfli, F. F., Mesa, J. M., Rocha, J. D., Filippetto, D., Luengo, C. A.; Pippo, W. A., Biomass briquetting and its perspectives in Brazil. Biomass and Bioenergy 2011, 35, 236. [CrossRef]

7 Garcia, R.; Pizarro, C.; Lavín, A. G.; Bueno, J. L. Characterization of Spanish biomass wastes for energy use. Bioresource Technology 2012, 103, 249. [CrossRef]

${ }^{8}$ Garcia, R.; Pizarro, C.; Lavín, A. G.; Bueno, J. L. Spanish biofuels heating value estimation Part II: Proximate analysis data. Fuel 2014, 117, 1139. [CrossRef]

${ }^{9}$ Demirbas, A. Combustion characteristics of different biomass fuel. Progress in Energy and Combustion Science 2004, 30, 219. [CrossRef]
${ }^{10}$ Grover, P. D.; Mishra, S. K. Biomass Briquetting: Technology and practices. FAO 1996. [Link]

${ }^{11}$ Tripathi, A. K.; Iyer, P. V. R.; Kandpal, T. C. A techno-economic evaluation of biomass briquetting in India. Biomass and Bioenergy 1998, 14, 479. [CrossRef]

${ }^{12}$ Yan, H.; Fujita, O. Study of the transient combustion of highly densified biomass briquette (Bio-coke) in an air-flow. Fuel 2017, 188, 595. [CrossRef]

${ }^{13}$ Granada, E.; López González, L.M.; Míguez, J.L.; Moran, J. Fuel lignocellulosic briquettes, die design and products study. Renewable Energy 2012, 27, 561. [CrossRef]

${ }^{14}$ Quirino, W. F.; Brito, J. O. Características e índice de combustão de briquetes de carvão vegetal. Série Técnica n13, 1991. [Link]

${ }^{15}$ Indústria Brasileira de Árvores, IBÁ, 2016. [Link]

${ }^{16}$ Companhia Nacional do Abastecimento, CONAB, 2016 [Link]

${ }^{17}$ Nakashima, G. T.; Martins, M. P.; Silva, D. A.; Chrisostomo, W.; Yamaji, F. M. Aproveitamento de resíduos vegetais para a produção de briquetes. Revista Brasileira de Ciências Ambientais 2014, 34, 22. [Link]

${ }^{18}$ Oliveira, A. A. G.; Pereira, J.; Alvarenga, T. M. P. Trabalho completo do II Congresso Brasileiro de plantas oleaginosas, óleos, gorduras e biodiesel, Lavras: Universidade Federal de Lavras, Brasil 2005. [Link]

${ }^{19}$ Telmo, C.; Lousada, J.; Moreira, N. Proximate analysis, backwards stepwise regression between gross calorific value, ultimate and chemical analysis of wood. Bioresource Technology 2010, 101, 3808. [CrossRef]

${ }^{20}$ Brand, M. A; Energia de biomassa florestal. Interciência: Rio de Janeiro, 2010.

${ }^{21}$ Mckendry, P. Energy production from biomass (part 1): overview of biomass. Bioresource Technology 2002, 83, 37. [CrossRef]

${ }^{22}$ Obernberger, I.; Thek, G. Physical characterization and chemical composition of densified biomass fuels with regard to their combustion behavior. Biomass \& Bioenergy 2004, 27, 653. [CrossRef] 
${ }^{23}$ Bridgeman, T. G.; Darvell, L. I.; Jones, J. M.; Williams, P. T.; Fahmi, R.; Bridgwater, A. V.; Barraclough, T.; Shield, I.; Yates, N.; Thain, S. C.; Donnison, I. S. Influence of particle size on the analytical and chemical properties of two energy crops. Fuel 2007, 86, 60. [CrossRef]

${ }^{24}$ Silva, D. A.; Nakashima, G. T.; Barros, J. L.; Da Róz, A. L.; Yamaji, F. M. Caracterização de biomassas para a briquetagem. Floresta 2015, 45, 713. [CrossRef]

${ }^{25}$ Kaliyan, N.; Morey, R. V. Factors affecting strength and durability of densified biomass products. Biomass \& Bioenergy 2009, 33, 337. [CrossRef]

${ }^{26}$ Gonçalves, B. F.; Yamaji, F. M.; Fernandez, B. O.; Róz, A. L.; Floriano, F. S. Caracterização e comparação entre diferentes granulometrias de serragem de Eucalyptus grandis para a confecção de briquetes. Revista do Instituto Florestal 2013, 25, 205. [Link]

27 Tamaki, Y.; Mazza, G. Measurement of structural carbohydrates, lignins, and microcomponents of straw and shives: Effects of extractives, particle size and crop species. Industrial Crops and Products 2010, 31, 534. [CrossRef]

${ }^{28}$ Demirbas, A. Relationships between heating value and lignin, moisture, ash, and extractive contents of biomass fuels. Energy Exploration \& Exploitation 2002, 20, 105. [CrossRef]

${ }^{29}$ Ghaffar, S. H.; Fan, M. Structural analysis for lignin charcateristics in biomass straw. Biomass \& Bioenergy 2013, 57, 264. [CrossRef]

${ }^{30}$ ASTM E871-82(2013), Standard Test Method for Moisture Content Analysis of Particulate Wood Fuels, ASTM International, West Conshohocken, PA, 2013. [Link]

${ }^{31}$ Hansted, A. L. S.; Nakashima, G. T.; Martins, M. P.; Yamaji, F. M. Caracterização físico-química da biomassa de Leucaena leucocephala para produção de combustível sólido. Revista Virtual de Química 2016, 8, 1449. [CrossRef]

${ }^{32}$ ABNT NBR 6922/81, Carvão vegetal Ensaios físicos determinação da massa específica (densidade à granel), Rio de Janeiro, RJ, 2014. [Link]
${ }^{33}$ ASTM D293-96(2010), Standard Test Method for Sieve Analysis of Coke, ASTM International, West Conshohocken, PA, 2010. [Link]

${ }^{34}$ ASTM D1102-84(2013), Standard Test Method for Ash in Wood, ASTM International, West Conshohocken, PA, 2013. [Link]

${ }^{35}$ Vassilev, S.V.; Baxter, D.; Andersen, L.K.; Vassileva, C.G.; Morgan, T.J. An overview of organic and inorganic phase composition of biomass. Fuel 2012, 94, 1. [CrossRef]

${ }^{36}$ ASTM E872-82 (2013), Standard test method for volatile matter in the analysis of particulate wood fuels, ASTM International, Phyladelphia, 2013. [Link]

37 ASTM D5865-13, Standard Test Method for Gross Calorific Value of Coal and Coke, ASTM International, West Conshohocken, PA, 2013. [Link]

${ }^{38}$ Martins, M. P; Benício, E. L.; Dias Júnior, A. F.; Almeida, R. B.; Carvalho, A. M.; Yamaji, F. M. Produção e avaliação de briquetes de finos de carvão vegetal compactados com resíduo celulósico proveniente da indústria de papel e celulose. Revista Árvore 2016, 40, 173. [CrossRef]

${ }^{39}$ Barros, J. L.; Dissertação de Mestrado, Universidade Federal de São Carlos, 2014. [Link]

${ }^{40}$ Sette Jr, C. R.; Freitas, P. C.; Freitas, V. P.; Yamaji, F. M.; Almeida, R. A. Production and characterization of bamboo pellets. Bioscience Journal 2016, 32, 922. [CrossRef]

${ }^{41}$ Teixeira, C. M. ; Martins, M. P. ; Yamamoto, H.; Chrisostomo, W. ; Yamaji, F. M. Caracterização Química de Resíduos de Eucalyptus sp. de Floresta de Curta Rotação para a Produção de Bioenergia. Revista Virtual de Química 2016, 8, 1693. [CrossRef]

${ }^{42}$ Santos, L. R. O.; Dissertação de Mestrado, Universidade Federal de São Carlos, 2015. [Link]

${ }^{43}$ Chrisostomo, W.; Dissertação de Mestrado, Universidade Federal de São Carlos, 2011. [Link]

${ }^{44}$ Tomeleri, J. O. P.; Trabalho de Conclusão de Curso, Universidade Federal de São Carlos, Campus Sorocaba, 2016. [Link] 
${ }^{45}$ Brasil, D. S.; Martins, M. P.; Nakashima, G. T.; Yamaji, F. M. Use of sugarcane bagasse and candeia waste for solid biofuels production. Floresta 2015, 45, 185. [CrossRef] ${ }^{46}$ Narita, D. K.; Trabalho de Conclusão de Curso, Universidade Federal De São Carlos, Campus Sorocaba, 2014. [Link]

${ }^{47}$ Hansted, A. L. S.; Nakashima, G. T.; Martins, M. P.; Yamamoto, H.; Yamaji, F. M. Comparative analyses of fast growing species in different moisture content for high quality solid fuel production. Fuel 2016, 184, 180. [CrossRef]

${ }^{48}$ Amaral, P. M.; Oliveira, P. B. M.; Yamaji, F. M.; Silva, D. A.; Silva, J. M. S.; Guerra, S. P. S. Caracterização química, física e mecânica de briquetes de duas variedades de bambu. Revista do Instituto Florestal 2015, 27, 73. [CrossRef]

${ }^{49}$ Durango, E. R. P. ; Adhmann, I. C. ; Yamaji, F. M.; Fandino, J. M. M. Produção e Caracterização Físico-Mecânica de Briquetes de Fibra de Coco e Palha de Cana-de-Açúcar. Revista Virtual de Química 2016, 8, 1334. [CrossRef]
${ }^{50}$ Scalet, V.; Dissertação de Mestrado, Universidade Federal de São Carlos, Campus Sorocaba, 2015. [Link]

${ }^{51}$ Greenhalf, C. E.; Nowakowski, D. J.; Yates, N.; Shield, I.; Bridgwater, A.V. The influence of harvest and storage on the properties of fast pyrolysis from Miscanthus $\mathrm{x}$ giganteus. Biomass and Bioenergy 2013, 56, 247. [CrossRef]

${ }^{52}$ TAPPI T $204 \mathrm{~cm}-97$. Solvent extractives of wood and pulp, 1997. [Link]

${ }^{53}$ TAPPI T $207 \mathrm{~cm}-99$. Water solubility of wood and pulp, 1999. [Link]

${ }^{54}$ TAPPI T 222 om-02. Acid-insoluble Lignin In Wood And Pulp, 2002. [Link]

${ }^{55}$ Associação Brasileira De Normas Técnicas NBR 7222/11. Concreto e argamassa Determinação da resistência à tração por compressão diametral de corpos de prova cilíndricos. Rio de Janeiro, RJ, 2011. [Link] ${ }^{56}$ Associação Brasileira De Normas Técnicas NBR 8740/85. Carvão vegetal - Determinação do índice de quebra e abrasão - Método de Ensaio. Rio de Janeiro, RJ, 2014. [Link] 